\title{
A Study of Early Schooling Children on Personality Factors
}

\author{
Dr. Bobinder ${ }^{1 *}$
}

\section{ABSTRACT}

The objective of this study was to measures of personality factors of children. Total sample consisted of 320 subjects (160 rural \& 160 urban children) were selected from the district of Baghpat (U.P.). A 2x2x2 factorial design was used. In each group of 160 subjects were 80 male and female early schooling and proper schooling. Early School Personality Questionnaire (E.S.P.Q.) was administered. There are two version of the tool i.e., English and Hindi, but here use only Hindi version standardized in Indian condition on population. E.S.P.Q. measure objectivity 13 primary personality dimensions as the child begins his school years. It is meant for the age group from 6 to 8 years. The result show that the time of schooling significantly affects the reserved/ outgoing personality factors of children. Subjects of early schooling has high mean score of factors A, while the subjects of proper schooling age has low mean scores. They were reserved detached, critical and cool.

Keywords: Early schooling, Proper schooling, Children Environment, Sex \& Personality Factors.

Since the sixth decade of the $21^{\text {st }}$ century in elementary education system it was a practice to admit children in schools in the $1^{\text {st }}$ grade at the age of 5 years. For the last 15 years, there has been a great change in the strategy regarding the schooling age of the children. In general practice now children are admitted at the early ages of 3 or 4 years and in some cases they are being admitted at the age of 2 years. To meet the requirements of early schooling at present children have to pass Nursery L.K.G., U.K.G. etc. The system of early schooling originated and developed in Western Countries. At the initial stag the 'care homes' were established in Western Countries, most probably for the children of employed parents, to tackle their custodial necessity and the problem of looking after them. Later, the organizers of such 'care homes' started to teach children something informal just to make their 'care homes' more attractive. It was the beginning of early schooling.

\footnotetext{
${ }^{1}$ Lecturer-Shri Sai Mahavidyalya, Fatehpur Putthi (Baghpat)

*Responding Author

(C) 2016 I Bobinder; licensee IJIP. This is an Open Access Research distributed under the terms of the Creative Commons Attribution License (http://creativecommons.org/licenses/by/2.0), which permits unrestricted use, distribution, and reproduction in any Medium, provided the original work is properly cited.
} 


\section{A Study of Early Schooling Children on Personality Factors}

Basically, the early schooling systems is in principle a process, a development oriented systems that must be implemented through the means of play and activity. It should be helping the children in their proper psycho-physical development by providing them independent opportunities to play act in their desired way. Unfortunately, the original system of early schooling has not been followed properly in general practice. With special references to the general practice to early schooling in India, the system has been broken and has become deviated from its basic goals and objectives of preschool education as incorporated in the report of the 'Education Commission' and the 'National Policy of Education'. The curriculum for the preschool is expected to be planed and transacted in such a way that the fulfill these objectives. But the curriculum practiced today is not conforming to these objectives. The stricture of preschool or early education has been drastically changed in general practice and it has become a 'stricture of formal education' instead of being informal, as required to be. The children are taught alphabets, numbers and tables etc. and are also given home work at this early age.

\section{Early Schooling}

The children who have been admitted to schools before five years of age have been kept in the early schooling group.

\section{Proper Schooling}

The children who have been admitted to school after or at five years of age, have been kept in the proper schooling group.

\section{Personality Factors}

A system of personality is based on the identification of personality traits and their measurement through factor analyses. Cattell defines personality in terms of "that which permits a prediction of what a person will do in a give situation."

\section{Children}

A child is a human between the stages to birth and puberty. The legal definition to childgenerally refers to a minor, otherwise known as a person younger than the age of majority. A person who has little or no experience in a particular area.

\section{Environment}

From the psychological view-point an individual's environment is related to all those stimuli which he confronts since the moment of fertilization till death-In other words, it influences all those factors which in any way influence an individual's development. Ordinarily, environment may be divided into two categories: the natural and the social. But Indian social set up has two dimensions i.e., rural and urban. Rural areas which are not urban shall be treated as rural while all areas which were identified as urban at the time of the 2011 census or subsequently notified to be so are to be treated as urban.

\section{Sex}

The role of sex is the most important in psychological development of students. It does not a only physiologically but also anatomically. Sex role, which plays a majors part in social behavior are established very early in life. In a new book Eleanor Maccoby has concluded that many beliefs about the differences in both sexes are unfounded and are clearly misconceptions. Recent 


\section{A Study of Early Schooling Children on Personality Factors}

evidence suggests that many sex differences probably due to leavening. Both factors like physiological and psychological are involved in sex role development.

\section{Statement the Problem}

The present study has been titled as 'A Study of Early Schooling Children on Personality Factors.'

\section{OBJECTIVES OF THE STUDY}

1. To study the effect of the early schooling on personality factors to children.

2. To determine the effect of the sex on personality factors of children.

3. To find out the effects of the environment on personality factors of children.

4. To study the interaction effects of early schooling and sex on personality factors of children.

5. To determine the interaction affects of sex and environment on the personality factors of children.

6. To find out interaction effects to early schooling and environment on the personality factors of children.

7. To study the interaction effects of the early schooling sex and environment on the personality factors of children.

\section{Hypothesis}

1. There will be no effects of early schooling on personality factors of children.

2. There will be no difference in the personality factors of males and females children.

3. There will be no effect of the environment on the personality factors of children.

4. There will be no interaction effects of the early schooling and sex on the personality factors of children.

5. There will be no interaction effects of the early schooling and sex on the personality factors of children.

6. There will be no interaction effects of the early schooling and environment on the personality factors of children.

7. There will be no interaction effects of the early schooling and sex and environment on the personality factors to the children.

\section{Variable Involved:}

Dependent Variable: Personality Factors

Independent Variable: Schooling age (early \& proper schooling), Sex (male \& female) Environment (rural and urban)

\section{Tools}

Hindi version of 'Early School Personality Questionnaire' (ESPQ) has been used to measure the personality factors of children. The questionnaire was originally constructed and standardized by Dr. Richard W. Coan University of Arizona, and Dr. Raymond B. Cattell, University of Illinois. It was originally published by the Institute for personality and ability testing 1966 . The special format of ESPQ measures objectivity 13 primary personality dimensions as the child begins has school years. Questions may be read aloud by the teacher and answers are marked on a pictorial 


\section{A Study of Early Schooling Children on Personality Factors}

answer booklet. The child needs only to be able to discriminate the letter A from the letter B and to recognize pictures of a bird, cat, tree, flower and other common objects. It is meant for the age group from 6 to 8 years. It is divided for convenience into two parts $-A_{1}$, and $A_{2}, 80$ items each.

\section{Administration of the Test}

Permission for the administration of the test E.S.P.Q. on the children studying in different schools of rural and urban areas of the Baghpat district was taken from the office of Basic Education Board and Basic Shiksha Adhikari (B.S.A.) of the Baghpat with the help of school records, a sample of 320 children (160 male and 162 female) has been selected for the research E.S.P.Q. part $A_{1}$, and part $A_{2}$ were administered to the children at different times. The test was administered (individually and in the small groups of 4-5 subjects) to the subjects of both sex. Instruction given in the (manual) guide book of E.S.P.Q. were strictly followed at the time to administration of the test.

\section{Scoring of the Test}

The responses of the subjects on the answer sheet were in the form of a cross (X) put on the letter ( $v$ or $\mathrm{c}$ ) which have been scored by the investigators himself, with the use to two specified scoring keys, which were designed for the both sides of the answer sheets.

\section{Nature of the Study}

Present research is 'Expost-Facto' by nature where independent variable is studied in retrospect for its possible effects on dependent variable. Literal meaning of 'expost-facto' is 'from what is done afterward', which is taken contrary to experimental by Kerlinger Freed N. 1966. Kerlinger defined it as - 'expost facto' research is systematic empirical inquiry in which the scientist does not have direct control of independent variables because their manifestations have already occurred or they are inherently not manipulable. Inferences about relations among variables are made without intervention, from concomitant variation of independent and dependent variables.

\section{Sample}

By space using the incidental purposive technique 8 years old, 320 subjects (which is the just double to the number of subjects proposed in the synopsis which was 160 subjects) studying in different schools of Baghpat district of Uttar Pradesh have been selected for the study. Distribution of sample with respect to schooling age, sex and environment.

\section{Statistical Technique}

The Analysis of Variance (ANOVA) technique was used to analyses the data obtained from thirteen factors of E.S.P.Q. and F-test, t-test also.

\section{REVIEW OF LITERATURE}

Achhpalet al (1991) studied the cognitive styles of 50 preschoolers and found that impulsive Ss were below their age level expectancy in terms of leaning abilities. Ss classified as reflective were either above or at their age level expectancy. Reflective Ss were shy, had few friends and did not generally participate in group activities. The importance of knowing childrens cognitive styles is stressed so that appropriate decision can be made regarding the development of suitable decision can be made regarding the development of suitable education programmer. Achenbach Tomes M. and Edel Brock, Craigs (1994) contend in this review of the literature on the 


\section{A Study of Early Schooling Children on Personality Factors}

Psychopathology of childhood, that problem of assessment and taxonomy have 100 the study of childhood disorders. Chhazan et. al (1984) studied the behavior problems in the infant schools on the two surveys of 26 urban schools. Changes over 2 years period are examined in terms of the overall incidence of behavior problems, incidence in different of types of catchment area, sex differences and the persistence and the development of behavior problems in individual cases. Relationship between problems in individual cases. Relationship between children's emotional and social adaptation level and their perception of teacher have been studied by Dabrowska, Jadviga (1989), on 68 nursery school children. Result show that on the whole there appears to be no relationship between a child's adaptation level and social caring and his/her perception of a teacher.

Review of recent clinical and epidemiological studies of the nature and incidence the behavior problems in various group of children has been made by Evans, E.G. (1986). Studies show that broken homes, long term family disturbance, unstable family relationship in the home, overcrowding, and poverty contribute to poor performance at school, anti-social behavior and psychological disturbance. In the field of treatment using behavior, suggests that this method may be more suitable than traditional approaches to discipline both in the home and the classroom. Hughes M. et.al (1989) found children's difficulties on starting infant school in 260 London children (4 years 3 month to 5 years 5 month age) in their $\mathrm{I}^{\text {st }}$ term nursery school were rated by their teachers, $13 \%$ were having general difficulties coping with school and approximately $25 \%$ had difficulties with language, persistence with activates and fine motor controls. Jenkins, R.L. Bold (1979) studied types of children's behavior disturbance. He discussed the relationship of 6 symptomatic types of children's behavior to characteristic family situation. The over anxious type is usually found in educated middle class families where high goals of success are stressed. Miller and others (1983) have found the prevalence of hyperactivity in a population of 849 suburban grade school children by use of teacher assessment. The problem in $93 \%$ of the 440 boys in $15 \%$ of the 409 girls in grades 3 to 6 . Scoperi A. Andreani (1986) studied 2 groups of 198 and 116 children attending school in areas of high and low social level respectively $36 \%$ of the whole sample had some problem of nursery school adjustment particularly in connection with socialization. Factor, David C. and Frankie, Gery H. (1990)_discussed the free play behavior of 19 socially maladjusted and 19 normal preschool children in their respective naturalistic settings. Results are discussed with regard to different setting for each for group of children and the ways in which specific teacher behaviors, such as teacher directiveness, may be related to the social status and social skill level of socially maladjusted children. Muralidharan, B. Rajalakshmi (1983) surveyed age trends in parentassessed behavior problem of 990, 3-8 years old school children. Behavior problems were found to decrease with increasing age, and to be highest in 3-4 years old and lowest in 7-8 years old subjects.

The relationship between internal-external control and behavior adjustment in 25 preschool boys and girls was investigated by Ollendick Duane G. and La Berteaux, Paul J. (1989). Results are 
contrary to the general hypothesis that high external locus of control would be positively related to greater behavior adjustment problems as has been found with some group to older children and adults.

Table No. 1. Summary of ANOVA: Factor A. Sizothymia/Affectothymia (cyclothymia)-

\begin{tabular}{|l|l|l|l|l|l|}
\hline Source of Variances & Sum of Squares & df & $\begin{array}{l}\text { Mean } \\
\text { Square }\end{array}$ & F-ratio & L.S. \\
\hline Time of Schooling & 79.06 & 1 & 79.06 & 11.55 & $* *$ \\
\hline Sex & 45.81 & 1 & 45.81 & 6.62 & $*$ \\
\hline Environment & 29.46 & 1 & 29.46 & 4.25 & $*$ \\
\hline Time of Sch. $\times$ Sex & 8.20 & 1 & 8.20 & 1.18 & \\
\hline Sex $\times$ En. & 0.07 & 1 & 0.07 & 0.01 & \\
\hline Time of Schooling $\times$ En. & 25.95 & 1 & 25.95 & 3.74 & \\
\hline Time of Sch. $\times$ Sex $\times$ En. & 3.94 & 1 & 3.94 & 0.56 & \\
\hline Within groups & 2164.80 & 312 & 6.93 & & \\
\hline
\end{tabular}

Table No. 2. Summary of ANOVA: Factor B. Lower Scholastic Mental Capacity vs. Higher Scholastic Mental Capacity-

\begin{tabular}{|l|l|l|l|l|l|}
\hline Source of Variances & Sum of Squares & df & $\begin{array}{l}\text { Mean } \\
\text { Square }\end{array}$ & F-ratio & L.S. \\
\hline Time of Schooling & 382.8 & 1 & 382.8 & 82.14 & $* *$ \\
\hline Sex & 3.19 & 1 & 3.19 & 0.68 & \\
\hline Environment & 1.79 & 1 & 1.79 & 0.38 & \\
\hline Time of Sch. $\times$. Sex & 0.13 & 1 & 0.13 & 0.02 & \\
\hline Sex $\times$ En. & 42.07 & 1 & 42.07 & 9.02 & $* *$ \\
\hline Time of Schooling $\times$ En. & 11.53 & 1 & 11.53 & 2.47 & \\
\hline Time of Sch. $\times$ Sex $\times$ En. & 10.77 & 1 & 10.77 & 2.31 & \\
\hline Within groups & 145467 & 312 & 4.66 & & \\
\hline
\end{tabular}

** Significant at. 01 level, * Significant at. 05 level

Table No. 3. Summary of ANOVA: Factors Lower Ego Strength vs. Higher Ego strength

\begin{tabular}{|l|l|l|l|l|l|}
\hline Source of Variances & Sum of Squares & df & $\begin{array}{l}\text { Mean } \\
\text { Square }\end{array}$ & F-ratio & L.S. \\
\hline Time of Schooling & 81.00 & 1 & 81.00 & 81.00 & $* *$ \\
\hline Sex & 45.75 & 1 & 45.75 & 45.75 & $* *$ \\
\hline Environment & 2.27 & 1 & 2.27 & 227 & $* *$ \\
\hline Time of Sch. $\times$ Sex & 0.03 & 1 & 0.03 & 3 & \\
\hline Sex $\times$ En. & 5.79 & 1 & 5.79 & 579 & $* *$ \\
\hline Time of Schooling $\times$ En. & 13.21 & 1 & 13.21 & 1321 & $* *$ \\
\hline Time of Sch. $\times$ Sex $\times$ En. & 0.0 & 1 & 0.0 & 00 & \\
\hline Within groups & 5.80 & 312 & 0.01 & & \\
\hline
\end{tabular}


Table No. 4. Summary of ANOVA: Factor D. Phlegmatic vs. Excitable-

\begin{tabular}{|l|l|l|l|l|l|}
\hline Source of Variances & Sum of Squares & If & $\begin{array}{l}\text { Mean } \\
\text { Square }\end{array}$ & F-ratio & L.S. \\
\hline Time of Schooling & 79.99 & 1 & 79.99 & 18.05 & $* *$ \\
\hline Sex & 44.99 & 1 & 44.99 & 10.15 & $* *$ \\
\hline Environment & 5.04 & 1 & 5.04 & 1.13 & \\
\hline Time of Sch. $\times$. Sex & 14.02 & 1 & 14.02 & 3.16 & \\
\hline Sex $\times$ En. & 1.76 & 1 & 1.76 & 0.39 & \\
\hline Time of Schooling $\times$ En. & 0.02 & 1 & 0.02 & 0.00 & \\
\hline Time of Sch. $\times$ Sex $\times$ En. & 2.91 & 1 & 2.91 & 0.65 & \\
\hline Within groups & 138482 & 312 & 4.45 & & \\
\hline
\end{tabular}

Table No. 5. Summary of ANOVA: Factor-E. only full stop Submissivenss vs. Dominace-

\begin{tabular}{|l|l|l|l|l|l|}
\hline Source of Variances & Sum of Squares & df & $\begin{array}{l}\text { Mean } \\
\text { Square }\end{array}$ & F-ratio & L.S. \\
\hline Time of Schooling & 28.78 & 1 & 28.78 & 11.69 & $* *$ \\
\hline Sex & 112.81 & 1 & 112.81 & 45.85 & $* *$ \\
\hline Environment & 12.01 & 1 & 12.01 & 488 & $*$ \\
\hline Time Sch. $\times$ Sex & 33.91 & 1 & 33.91 & 13.78 & $* *$ \\
\hline Sex $\times$ En. & 1.68 & 1 & 1.68 & 0.68 & \\
\hline Time of Schooling $\times$ En. & 135.81 & 1 & 135.81 & 55.20 & $*$ \\
\hline Time of Sch. $\times$ Sex $\times$ En. & 2.79 & 1 & 2.79 & 1.13 & \\
\hline Within groups & 768.09 & 312 & 2.46 & & \\
\hline
\end{tabular}

Table No. 6. Summary of ANOVA: Factor-F. Desurgency vs. Surgency-

\begin{tabular}{|l|l|l|l|l|l|}
\hline Source of Variances & Sum of Squares & df & $\begin{array}{l}\text { Mean } \\
\text { Square }\end{array}$ & F-ratio & L.S. \\
\hline Time of Schooling & 33.15 & 1 & 33.15 & 1.97 & $* *$ \\
\hline Sex & 8.77 & 1 & 8.77 & 2.90 & \\
\hline Environment & 3.4 & 1 & 3.4 & 1.12 & \\
\hline Time Sch. $\times$ Sex & 0.01 & 1 & 0.01 & 0.00 & \\
\hline Sex $\times$ En. & 1.96 & 1 & 1.96 & 0.64 & \\
\hline Time of Schooling $\times$ En. & 0.03 & 1 & 0.03 & 0.00 & \\
\hline Time of Sch. $\times$ Sex $\times$ En. & 0.0 & 1 & 0.0 & 0.00 & \\
\hline Within groups & 943.30 & 312 & 3.02 & & \\
\hline
\end{tabular}


Table No. 7. Summary of ANOVA: Factor-G. Weaker Super Ego Strength vs. Stronger Super Ego Strength-

\begin{tabular}{|l|l|l|l|l|l|}
\hline Source of Variances & Sum of Squares & If & $\begin{array}{l}\text { Mean } \\
\text { Square }\end{array}$ & F-ratio & L.S. \\
\hline Time of Schooling & 45.75 & 1 & 45.75 & 14.34 & $* *$ \\
\hline Sex & 0.38 & 1 & 0.38 & 0.11 & \\
\hline Environment & 0.7 & 1 & 0.7 & 0.21 & \\
\hline Time Sch. $\times$ Sex & 0.03 & 1 & 0.03 & 0.00 & \\
\hline Sex $\times$ En. & 0.26 & 1 & 0.26 & 0.08 & \\
\hline Time of Schooling $\times$ En. & 12.87 & 1 & 12.87 & 4.03 & $*$ \\
\hline Time of Sch. $\times$ Sex $\times$ En. & 10.38 & 1 & 10.38 & 3.25 & \\
\hline Within groups & 996.76 & 312 & 3.19 & & \\
\hline
\end{tabular}

Table No. 8. Summary of ANOVA: Facter-H. Threctia vs. Parmia-

\begin{tabular}{|l|l|l|l|l|l|}
\hline Source of Variances & Sum of Squares & df & $\begin{array}{l}\text { Mean } \\
\text { Square }\end{array}$ & F-ratio & L.S. \\
\hline Time of Schooling & 48.85 & 1 & 48.82 & 16.71 & ** \\
\hline Sex & 77.02 & 1 & 77.02 & 26.37 & ** \\
\hline Environment & 0.02 & 1 & 0.02 & 0.00 & \\
\hline Time Sch. $\times$ Sex & 3.42 & 1 & 3.42 & 1.17 & \\
\hline Sex $\times$ En. & 0.02 & 1 & 0.02 & 0.00 & \\
\hline Time of Schooling $\times$ En. & 0.08 & 1 & 0.08 & 0.02 & \\
\hline Time of Sch. $\times$ Sex $\times$ En. & 5.23 & 1 & 5.23 & 1.63 & \\
\hline Within groups & 913.64 & 312 & 2.92 & & \\
\hline
\end{tabular}

Table No. 9. Summary of ANOVA: Factor-I. Harria vs. Premsia-

\begin{tabular}{|l|l|l|l|l|l|}
\hline Source of Variances & Sum of Squares & df & $\begin{array}{l}\text { Mean } \\
\text { Square }\end{array}$ & F-ratio & L.S. \\
\hline Time of Schooling & 79.99 & 1 & 79.99 & 33.60 & $* *$ \\
\hline Sex & 84.04 & 1 & 84.04 & 35.31 & $* *$ \\
\hline Environment & 0.31 & 1 & 0.31 & 0.13 & \\
\hline Time Sch. $\times$ Sex & 3.63 & 1 & 3.63 & 1.52 & \\
\hline Sex $\times$ En & 0.01 & 1 & 0.01 & 0.00 & \\
\hline Time of Schooling $\times$ En. & 0.06 & 1 & 0.06 & 0.02 & \\
\hline Time of Sch. $\times$ Sex $\times$ En. & 20.97 & 1 & 20.97 & 8.81 & $* *$ \\
\hline Within groups & 743.88 & 312 & 2.38 & & \\
\hline
\end{tabular}


Table No. 10. Summary of ANOVA: Factor. J. Zeppia vs. Goasthenia-

\begin{tabular}{|l|l|l|l|l|l|}
\hline Source of Variances & Sum of Squares & df & $\begin{array}{l}\text { Mean } \\
\text { Square }\end{array}$ & F-ratio & L.S. \\
\hline Time of Schooling & 56.11 & 1 & 56.11 & 20.11 & $* *$ \\
\hline Sex & 7.81 & 1 & 7.81 & 2.79 & \\
\hline Environment & 68.44 & 1 & 68.44 & 24.53 & $* *$ \\
\hline Time Sch. $\times$ Sex & 0.31 & 1 & 0.31 & 0.11 & \\
\hline Sex $\times$ En. & 7.21 & 1 & 7.21 & 2.58 & \\
\hline Time of Schooling $\times$ En. & 14.45 & 1 & 14.45 & 5.17 & $* *$ \\
\hline Time of Sch. $\times$ Sex $\times$ En. & 4.04 & 1 & 4.04 & 1.44 & \\
\hline Within groups & 873.12 & 312 & 2.79 & & \\
\hline
\end{tabular}

Table No. 11. Summary of ANOVA: Factor-N Artlessness vs. Shrewdness-

\begin{tabular}{|l|l|l|l|l|l|}
\hline Source of Variances & Sum of Squares & df & $\begin{array}{l}\text { Mean } \\
\text { Square }\end{array}$ & F-ratio & L.S. \\
\hline Time of Schooling & 189.1 & 1 & 189.1 & 55.13 & $* *$ \\
\hline Sex & 46.5 & 1 & 46.5 & 13.55 & $* *$ \\
\hline Environment & 103.9 & 1 & 103.9 & 30.29 & $* *$ \\
\hline Time Sch. $\times$ Sex & 8.47 & 1 & 8.47 & 2.46 & \\
\hline Sex $\times$ En. & 2.82 & 1 & 2.82 & 0.82 & \\
\hline Time of Schooling $\times$ En. & 5.67 & 1 & 5.67 & 1.65 & \\
\hline Time of Sch. $\times$ Sex $\times$ En. & 9.47 & 1 & 9.47 & 2.76 & \\
\hline Within groups & 1071.62 & 312 & 3.43 & & \\
\hline
\end{tabular}

Table No. 12. Summary of ANOVA: Factor- O. Untroubled Adeguacy vs. Guiet Proneness-

\begin{tabular}{|l|l|l|l|l|l|}
\hline Source of Variances & Sum of Squares & df & $\begin{array}{l}\text { Mean } \\
\text { Square }\end{array}$ & F-ratio & L.S. \\
\hline Time of Schooling & 93.53 & 1 & 93.53 & 23.44 & $* *$ \\
\hline Sex & 42.78 & 1 & 42.78 & 10.72 & $* *$ \\
\hline Environment & 10.15 & 1 & 10.15 & 2.54 & \\
\hline Time Sch. $\times$ Sex & 2.63 & 1 & 2.63 & 0.65 & \\
\hline Sex $\times$ En. & 24.78 & 1 & 24.78 & 6.21 & $*$ \\
\hline Time of Schooling $\times$ En. & 0.01 & 1 & 0.01 & 0.00 & \\
\hline Time of Sch. $\times$ Sex $\times$ En. & 3.34 & 1 & 3.34 & 0.83 & \\
\hline Within groups & 1247.26 & 312 & 3.99 & & \\
\hline
\end{tabular}


Table No. 13. Summary f ANOVA: Factor-Q4. Low Ergic Tentionsvs. High Ergic Tension-

\begin{tabular}{|l|l|l|l|l|l|}
\hline Source of Variances & Sum of Squares & df & $\begin{array}{l}\text { Mean } \\
\text { Square }\end{array}$ & F-ratio & L.S. \\
\hline Time of Schooling & 234.6 & 1 & 234.6 & 17.27 & $* *$ \\
\hline Sex & 10.5 & 1 & 10.5 & 0.77 & \\
\hline Environment & 8.44 & 1 & 8.44 & 0.62 & \\
\hline Time Sch. $\times$ Sex & 1.82 & 1 & 1.82 & 0.13 & \\
\hline Sex $\times$ En. & 27.63 & 1 & 27.63 & 2.03 & \\
\hline Time of Schooling $\times$ En. & 6.63 & 1 & 6.63 & 0.48 & \\
\hline Time of Sch. $\times$ Sex $\times$ En. & 0.42 & 1 & 0.42 & 0.03 & \\
\hline Within groups & 4238.16 & 312 & 13.58 & & \\
\hline
\end{tabular}

\section{RESULT AND DISCUSSION}

Table no.1 shows that subject of early schooling have high mean score on factor A, it indicates that subjects of early schooling were out - going, warm-heated, easy going, and participating, while the subjects of proper schooling age have low mean scores. They were reserved, detached, critical and cool. Female subjects were high scores. They were outgoing, warm - hearted, easy going and participating. While the male subjects have a low mean score. They were reserved, detached, critical and cool. Mean score of the rural subjects were high. They were outgoing, warm - hearted, easy going and participating, while the male subjects urban locality have a low mean score. They were reserved, detached, critical and cool. Table no. 2 indicate that subjects of early schooling were more intelligent, abstract thinking and bright, while the subjects of proper schooling age were less intelligent, concrete thinking and with lower scholastic mental capacity. Male subject of urban environment were more intelligent than the subjects of rural environment were more intelligent than the female subject to urban environment.

Table no. 3 shows that the subjects of early schooling age have higher strength. They were emotionally stable, reality-facing and calm while the subjects of proper schooling age lower ego strength. They were affected by felling, emotionally less stable and easily upset. Sex significantly affects the ego strength of children. Female subject have higher ego strength. They were emotionally stable, reality-facing and calm while male subjects have low ego strength. They were affected by feelings, emotionally less stable and easily upset. Environment significantly affects the ego strength of children. Subjects of rural have higher ego strength. They were emotionally stable, reality facing and calm, while the subjects of urban have lower ego strength. They were affected by feelings, emotionally less stable and easily upset. Interaction of sex and environment significantly affects the ego strength to children. Male subjects of rural have higher ego strength. They were emotionally stable, reality - facing, calm while the subjects of urban have lower ego strength. They were affected by feelings, emotionally less stable and environment significantly affects the ego strength of children. Subjects of early schooling age of rural and higher strength. They were emotionally stable, reality-facing and calm while the early schooling age subjects of urban environment have lower ego strength. They were affected by feelings emotionally less stable, early upset. Subjects to proper schooling from urban 


\section{A Study of Early Schooling Children on Personality Factors}

environment have higher ego strength. They were emotionally stable, reality-facing, clam while the subjects of proper schooling age of rural environment have lower ego strength. They were affected by feelings, emotionally less stable and easily upset.

Table no. 4 shows that results revealed that the children of proper schooling have a high mean score. They were impatient demanding and overactive, while the children of early schooling age were deliberate, inactive and stodgy. Female subject have high mean score. They were impatient, demanding, overactive, while the male subjects have a low mean score. They were deliberating inactive and study.

Table no. 5 indicates that Subjects of proper schooling age have high mean score. They were independent aggressive, stubborn, while the subjects of early schooling age have a low mean score. They were mild, conforming, submissive and obedient. Male subjects have a high mean score on factor E. They were assertive, independent, aggressive and stubborn, while the female subjects have a low mean score on factor E. They were obedient, mild, conforming and submissive. Subjects of rural environment have a high mean score on factor E. They were assertive, independent aggressive, stubborn and dominant, while the subjects of urban environment were obedient mild, conforming and submissive. Interaction of time of schooling and sex significantly the personality factors of children on factor E. Male subjects of early schooling have a high mean score. They were assertive, independent, aggressive, stubborn and dominant, while the male subjects of proper schooling age have a low mean score. They were obedient, mild, conforming and submissive, Female subjects of early schooling age have a low mean score. They were obedient, mild, conforming and submissive while the female subjects of proper schooling age have a high mean score. They were assertive, independent, aggressive, stubborn and dominant. Early schooling subjects of rural environment have a high mean score. They were assertive, independent, stubborn and dominant while the early schooling subjects of urban environment have a low mean score. They were obedient, mild, conforming and submissive. Proper schooling age subjects of rural environment have a high mean score. They were assertive independent, aggressive, stubborn and dominant while the proper schooling age subjects of urban environment have a low mean score. They were obedient, mild, conforming and submissive.

Table no. 6 shows that subjects of early schooling age have a high mean score. They were sober, prudent, serious, taciturn, while the subjects of proper schooling age have a low mean score. They were happy go-lucky-gay, enthusiastic and impulsively lively. Table no. 7 indicate that subjects of early schooling age have high mean score. They were conscientious, persevering, staid, rule-bound and have stronger super ego strength, while the subjects of proper schooling age have a low mean score. They were expedient, evading rules, felling few obligations and have weaker super ego strength. Early schooling subjects of rural environment have high mean score. They were conscientious, persevering, staid, rule bound and have stronger super ego strength, while the early schooling age subjects of urban environment have a low mean score. They were 


\section{A Study of Early Schooling Children on Personality Factors}

expedient, evading rules, feeling few obligations and have weaker super ego strength. Proper schooling age subjects of urban environment have high score. They were conscientious, persevering, staid, rule bound and have strength super ego strength, while the proper schooling age subjects of rural environment have a low mean score. They were expedient, evading rules, feeling few obligations and have weaker super ego strength.

Table no. 8 shows that early schooling age subjects have high mean score. They were venturesome, socially bold, uninhibited, spontaneous, while proper schooling age subjects have low mean score. They were shy, restrained, and diffident and tried. Female subjects have high mean score. They were venturesome, socially bold, uninhibited, spontaneous, while the male subjects have low mean score. They were sky, restrained, diffident and timid. Table no. 9 indicates that early schooling subjects have high mean score. They were tender minded, dependent, over prospected and sensitive, while the proper schooling age subjects and have low mean score. They were tough minded, self-reliant, realistic and no-nonsense. Female subjects have high mean score. They were tender minded, dependent, over protected, sensitive, while the male subjects have low score. They were tough minded, self-reliant, realistic, and no-nonsense. Interaction of fine of schooling, sex and environment significantly affect the personality factors of children on factors I. Interaction of all these independent variable affects the basic pattern of children's maintaining tough and/or tender mindedness.

Table no. 10 indicates that Subjects of early schooling age have low mean score. They were vigorous, readily going with group, zestful and given to action, while the subjects of proper schooling age have high mean score. They were doubting, obstructive individualistic reflective, internally restrained, unwilling to act. Subjects of rural environment have high mean score. They doubted, obstructive, individualistic, reflective, internally restriped and unwilling to act while urban subjects have low mean score. They were vigorous, readily going with group, zestful and given to action. Early schooling age subjects of rural environment have high mean score. They doubted, obstructive, individualistic, reflective, internally restrained and unwilling to act, while the urban subjects of early schooling age have low mean score. They were vigorous, readily going with group, zestful and given to action. Proper schooling age subjects of rural locality have a high mean score. They were doubting, obstructive, individualistic, reflective internally restrained and unwilling to act, while the urban proper schooling age subjects have low mean score. They were vigorous, readily going with group, zestful and given to action.

Table no. 11 shows that early schooling age subjects have a low mean score. They were forthright, natural artless, Sentimental while the proper schooling age subjects have high mean score. They were shrewd, calculating, world and penetrating. Male subjects have high mean score. They were shrewd, calculating, worldly, penetrating, while the female subjects have low mean score. They were forthright, natural artless, and Sentimental. Subjects of rural environment have high mean score. They were shrewd, calculating, worldly and penetrating, while urban subjects have low mean score. They were forthright, natural, artless, and Sentimental. Table no. 


\section{A Study of Early Schooling Children on Personality Factors}

12 indicate that subjects of early schooling age have low mean score. They were placid secure, confident and untroubled while the subjects of proper schooling age have high mean score. They were apprehensive, worrying, depressive, troubled, and insecure with guilt proneness. Male subject have high mean score. They were apprehensive worrying, depressive, troubled and insecure, while female subjects have low mean score. They were placid, secure, confident and untroubled. Male subjects of rural environment have high mean score. They were apprehensive worrying, depressive, troubled and insecure, while the male subject of urban environment have low mean score. They were placid, secure, confident and untroubled. Female subjects of rural environment have low mean score. They were placid, secure, confident and untroubled, while the female subject to urban environment have high mean score. They were apprehensive, worrying, depressive, troubled, insecure, and guilt prone. And lastly here table no. 13 shows that Subjects t early schooling age have low mean score. They were relaxed, tranquil, torpid and unfrustrated, while the proper schooling age subjects have high mean score. They were tense, driven, overwrought and frustrated.

\section{CONCLUSION}

To conclusion can that time of schooling has affected all the 13 factors of E.S.P.Q. significantly. Sex differences have been found significant on 8 factors of E.S.P.Q. viz-siziothymia vs. affectothymia (A), lower-ego strength vs. higher ego strength (C), Phlegmatic temperament vs. excitability (D), submissiveness vs. dominance (E), threctia vs. parmia (H), harmia vs. prensia (I), artlees vs. shrewdness (H), and untroubled adeguacy vs. guilt-proneness (O), Environment significantly the five factors of E.S.P.Q. viz. sigothymia vs. affectothynia (A), lower ego strength vs. higher ego strength (C), submissiveness vs. dominance (E), zeppia vs. coasthenia (J), artlessness vs. shrewdness (H), Interaction effects have been found significant on 7 factors vig lower scholastic mental capacity vs. higher scholastic mental capacity (B, sex $\times$ en.), lower ego strength vs. higher ego strength ( $C$, sex $\times$ en, time of schooling $\times$ en.), sabmissiveness vs. dominame (E, time of schooling $\times$ sex, time of schooling $\times$ en.), weaker super ego strength vs. stronger super ego strength (G, time of schooling $\times$ sex $\times$ en.), harria vs. premsia (I,time of schooling $\times$ sex en.), zeppia vs. coasthenia (J, time to schooling $\times$ en.), untroubled adeguancy vs. guilt proneness $(\mathrm{O}$,sex $\times$ en.).

\section{REFERENCE}

Achenbach Thomas, M \& Edelbrock, Craig S. (1994). Psychopathology of childhood. Annual Review of Psychology, Vol. 35, 227-256.

Achhpal, Beena \& Mistry, Verma. (1991). The cognitive styles among preschoolers and its relationship to teacher's rating on learning abilities. Child Psychiatry Qauarterly, octDec, Vol. 14(4), 126-132.

Bobinder (2015). A study of the attitude of Schior secondary students of Baghpat (U.P.) towards English as a medium of instruction. The International Journal of Indian Psychology, OctDec, Vol. 3,(4), 128-135. 


\section{A Study of Early Schooling Children on Personality Factors}

Chazan, Maurice \& Jackson, Susan. (1984). BEhaviour problems in the infant school: changes over two years. Journal of Child Psychology \& Psychiatry \& Allied Disciplines, Jan-Vol. 15(1), 33-46.

Dabrowaska, Jadwiga. (1989). Perception of teacher by nursery school children (Higher Padegological school by Dgoszez, Poland). Psychological Waweza, May-Jun, Vol. 22(3), 384-392.

Evans, E.G. (1986). Behaviur problems in children (Inner London Education Authority, England). Child Care Health and Development, Feb, Vol. 2(1), 35-43.

Factor, David C. \& Frankie, Garg.H. (1990). Free play behaviors in socially maladjusted and normal pre-school children: A Naturalistic Study. Canadian Journal of Behavioural Science, Jul, Vol. 12(3), 272-277.

Huhes, Martin, Pinkerton, Gill \& Plewis, Ian. (1989). Children's difficulties on sarting infant school. Journal of Child Psychology \& Psychiatry and Allied Disciplines. Jul, Vol. 20(3), 187-196.

Jenkins, Richard. L. (1979). Classification of behavior problems of children. American Journal of Psychiatry. Vol. 125(8), 1032-1039.

Miller, Ray G., Palkes, Helen S. \& Stewart, Mark, A. (1983). Hyperactive children in suburban elementary schools. Child Psychiatry and Human Developments, Vol, 4(2), 121-127.

Muralidharan, B. Rajlakshi (1983). Age trends in behavior problems of children. In T.E. Shanmungam (Ed). Researchers in personality and social problems. University of Madras, XVI, 324.

Ollendick, Dunae G. \& Laberteaux, Paul. J. (1989). Locus of control \& teacher ratings of behavious problems in pre-schoolers. Journal of Psychology, May, Vol. 9 (1), 1-18.

Scoperi, A. Andreani. (1986). Study of Psychological problems of adaptation to nursery school. Bulletin The Psychology Applied, Aug-Dec, No. 136-138, 23-37. 